\title{
Concept of Spondyloarthritis (SpA)
}

\section{Mohammad Bagher Owlia ${ }^{1 *}$ and Sina Owlia ${ }^{2}$}

${ }^{1}$ Department of Medicine, Shahid Sadoughi University of Medical Sciences, Yazd, Iran ${ }^{2}$ Medical Researcher, JCRP Research Team, Yazd, Iran

Rheumatic processes may involve almost any organ in the body. Different rheumatic conditions are classified based on clinical, imaging, laboratory and pathophysiologic standpoint. Rheumatoid arthritis and some other rheumatic conditions may involve peripheral joints in their classic form. Albeit not consistent, but internal organ involvement is not rare in systemic rheumatic disorders. Involvement of axial skeleton however is considered hallmark of a category of systemic rheumatic diseases namely seronegative spondyloarthritides (SpA). In this wide category of conditions, TNF mediated immune response targets axial skeleton including cervical, thoracic, lumbar and most importantly sacroiliac joints. Starting point of cascade events in SpA could be the enthesis i.e. the point at which a tendon or ligament or muscle inserts into bone. Due to a more abundant and complexity of numerous entheses, axial skeleton might be the target anatomy. Tendency toward this type of rheumatic invasion is mainly orchestrated by a strong genetic background. HLA-B27 genes play an important role in this disease spectrum. This role is so important that many researchers use the term "HLA-B27 associated syndrome" [1]. Molecular mimicry with some enteric bacteria such as Shigella, Yersinia and also Klebsiella pneumonia, may also have some role in pathogenesis of SpA [2].

Inflammatory spinal pain including neck, thoracic cage (back or chest wall) or lumbosacral pain is the initial presenting feature in near all cases. By definition, Inflammatory spinal pain is a kind of spinal pain that begins before age 40 , exacerbates with prolonged immobility or rest and is ameliorated with regular warming-up exercise and nonsteroidal anti-inflammatory agents [3]. Other unique and perhaps rare features of $\mathrm{SpA}$ are aortitis and isolated uveitis [4,5].

Considering above statements, a growing number of spinal pains (neck or back) and also chest wall pain may put into this category [6]. An important and disturbing fact is ignoring this common illness and mislabeling them as neurotic, discogenic or psychotic pain and of course seronegative brucellosis, polymyalgia rheumatica or malingering pain among clinicians and even specialists $[7,8]$.

There are several types of conditions under the heading of SpA. They include: Ankylosing spondylitis (AS), psoriatic arthritis (PsA), inflammatory bowel disease associates arthropathy, reactive arthritis (ReA). Some authors also include Behcet's disease and Whipples' disease within this spectrum.

A critical point to optimal understanding concept of SpA is slow progression of skeletal changes over time. So, in most cases the sole component of SpA spectrum could be subjective inflammatory spinal pain for weeks or months before other objective physical findings of established SpA or AS are not evident. After careful family and history taking and thorough physical examination for possible enthesitis from occipital bone, interspinous ligaments to Achilles tendon, sacroiliac joint tenderness is very important clinical finding. The next clue to diagnosis is searching for serum acute phase reactants for example C-reactive protein or less probably elevated erythrocyte sedimentation rate or evidence for chronic inflammation such as anemia of chronic diseases. Although classic serologic factors of rheumatism such as rheumatoid factor (RF) and antinuclear antibodies (ANAs) are basically negative, we frequently observe positive anti-CCP (anti-cyclic citrullinated peptide) titers in Iranian patients with $\mathrm{SpA}$ spectrum or even classic AS patients (unpublished data). So nomenclature of seronegative SpA might be subjected to a historical change in future. HLA typing could be of some help in some instances and most clinicians expect to have positive results in more than half of SpA spectrum and especially AS (about $90 \%$ positive).

Today, imaging techniques are proved to be very important tool for establishing diagnosis of SpA. Fat suppressed magnetic resonance imaging (MRI) is standard imaging technique in order to show very early changes within target joints or bone. These findings are usually depicted as synovitis, marrow edema and signal changes in STIR (Short TI Inversion Recovery) sequences in sacroiliac joints or hypersignal lesions in T2 weighted images of involved vertebrae as shiny corner or so-called inflammatory Schmorl's node or new proposed name of "Owlia's node" [4]. These findings are very diagnostic in case of inflammatory low back pain initiated before age forty [5]. Due to poor sensitivity and specificity, Isotope bone scan should not be used for routine assessment of sacroiliitis.

Take home message: Spondyloarthritides are common and missed diagnoses of them are more common in clinical practice! We think separation of different subtypes of diseases under a specific terminology, should not impose underestimation and under diagnosis of full disease spectrum not only for HLA-B27 associated diseases but also for other common rheumatic disorders in clinical practice [9].

\section{References}

1. Bergfeldt L, Insulander P, Lindblom D, Möller E, Edhag O (1988) HLA-B27: an important genetic risk factor for lone aortic regurgitation and severe conduction system abnormalities. Am J Med 85: 12-18.

2. Ebringer A, Ahmadi K, Fielder M, Rashid T, Tiwana H, et al. (1996) Molecular mimicry: the geographical distribution of immune responses to Klebsiella in ankylosing spondylitis and its relevance to therapy. Clin Rheumatol 15 Suppl 1: $57-61$.

3. Weisman MH, Witter JP, Reveille JD (2013) The prevalence of inflammatory back pain: population-based estimates from the US National Health and Nutrition Examination Survey, 2009-10. Ann Rheum Dis 72: 369-373.

4. Owlia MB, Farahifard $P$ (2012) Historical Schmorl's Node: Time to Differentiation and Renaming (A Mini- Review). J Spine 2: 1-3.

5. Maksymowych WP, Lambert RG, Brown LS, Pangan AL (2012) Defining the Minimally Important Change for the SpondyloArthritis Research Consortium of Canada Spine and Sacroiliac Joint Magnetic Resonance Imaging Indices for Ankylosing Spondylitis. J Rheumatol 39: 1666-1674.

6. Wendling D, Prati C, Demattei C, Loeuille D, Richette P, et al. (2013) Anterior Chest Wall Pain in Recent Inflammatory Back Pain Suggestive of Spondyloarthritis. Data from the DESIR Cohort. J Rheumatol 40: 1148-1152.

7. Aydeniz A, Altındağ O, Oğüt E, Gürsoy S (2012) Late onset spondyloarthropathy mimicking polymyalgia rheumatica. Rheumatol Int 32: 1357-1358.

*Corresponding author: Mohammad Bagher Owlia, Department of Medicine, Shahid Sadoughi University of Medical Sciences, Yazd, Iran, E-mail: bagherowlia@gmail.com

Received July 06, 2013; Accepted July 09, 2013; Published July 11, 2013

Citation: Owlia MB, Owlia S (2013) Concept of Spondyloarthritis (SpA). J Spine 2 e110. doi:10.4172/2165-7939.1000e110

Copyright: @ 2013 Owlia MB, et al. This is an open-access article distributed under the terms of the Creative Commons Attribution License, which permits unrestricted use, distribution, and reproduction in any medium, provided the original author and source are credited. 
8. Bouaziz MC, Bougamra I, Kaffel D, Hamdi W, Ghannouchi M, et al. (2010) Noncontiguous multifocal spondylitis: an exceptional presentation of spinal brucellosis. Tunis Med 88: 280-284.
9. Owlia M, Mirzaei M (2013) Hidden Spectrum of diseases and "case reporting". Journal of Case Reports in Practice 1: 24-25.

\footnotetext{
This article was originally published in a special issue, Inflammatory Spinal Disorders handled by Editor. Dr. Mohammad Bagher Owlia, University of Medical Sciences, Iran
} 